\title{
Biosynthesis of an Endogenous Cannabinoid Precursor in Neurons and its Control by Calcium and cAMP
}

\author{
Hugues Cadas, ${ }^{1}$ Sylvie Gaillet, ${ }^{2}$ Massimiliano Beltramo, ${ }^{1}$ Laurent Venance, ${ }^{2}$ and Daniele Piomelli ${ }^{1}$ \\ 1The Neurosciences Institute, San Diego, California 92121, and 'Institut National de la Santé et de la Recherche \\ Médicale, Paris, France
}

Understanding the mechanisms involved in the biogenesis of $\mathrm{N}$-arachidonoylethanolamine (anandamide) and $\mathrm{N}$ palmitoylethanolamine is important in view of the possible role of these lipids as endogenous cannabinoid substances. Anandamide (which activates cannabinoid CB1 receptors) and $N$-palmitoylethanolamine (which activates a CB2-like receptor subtype in mast cells) may both derive from cleavage of precursor phospholipid, $\mathrm{N}$-acylphosphatidylethanolamine (NAPE), catalyzed by $\mathrm{Ca}^{2+}$-activated $\mathrm{D}$-type phosphodiesterase activity. We report here that the de novo biosynthesis of NAPE is enhanced in a $\mathrm{Ca}^{2+}$-dependent manner when rat cortical neurons are stimulated with the $\mathrm{Ca}^{2+}$-ionophore ionomycin or with membrane-depolarizing agents such as veratridine and kainate. This reaction is likely to be mediated by a neuronal
$\mathrm{N}$-acyltransferase activity, which catalyzes the transfer of an acyl group from phosphatidylcholine to the ethanolamine moiety of phosphatidylethanolamine. In addition, we show that $\mathrm{Ca}^{2+}$-dependent NAPE biosynthesis is potentiated by agents that increase cAMP levels, including forskolin and vasoactive intestinal peptide. Our results thus indicate that NAPE levels in cortical neurons are controlled by $\mathrm{Ca}^{2+}$ ions and cAMP. Such regulatory effect may participate in maintaining a supply of cannabimimetic $\mathrm{N}$-acylethanolamines during synaptic activity, and prime target neurons for release of these bioactive lipids.

Key words: anandamide; N-acylethanolamines; phosphatidylethanolamine; N-acylphosphatidylethanolamine; N-acyltransferase; vasoactive intestinal peptide; endogenous cannabinoids
There is evidence that $N$-arachidonoylethanolamine (anandamide) and other $\mathrm{N}$-acylethanolamines (NAEs) act as intercellular signaling molecules in neural and non-neural tissues. Anandamide activates CB1-type cannabinoid receptors in brain and mimics many distinctive psychotropic effects typical of cannabinoid drugs (Devane et al., 1992) (for review; see Mechoulam et al., 1994). Similar effects are produced by other polyunsaturated NAEs (Hanuš et al., 1993). In addition, anandamide may have effects that are independent of the stimulation of CB1 and CB2 receptors. In striatal astrocytes, anandamide selectively decreases gapjunction permeability, but this effect is not mimicked by cannabinoid drugs and it is not prevented by a CB1-receptor antagonist (Venance et al., 1995). Saturated NAEs may also be biologically active and, in some cases, participate in cannabimimetic signaling. For instance, $N$-palmitoylethanolamine activates a CB2-like cannabinoid receptor present on mast cells (Facci et al., 1995).

Biochemical evidence indicates that endogenous NAEs are produced in and released from neurons in a $\mathrm{Ca}^{2+}$ - and activitydependent manner (Di Marzo et al., 1994; Hansen et al., 1995). Furthermore, as expected for a signaling molecule, anandamide is short-lived: its lifespan is limited by uptake into neural cells (Di

\footnotetext{
Received Feb. 14, 1996; revised March 27, 1996; accepted April 1, 1996.

Initial experiments were carried out at the Centre Paul Broca of Institut National de la Santé et de la Recherche Médicale, Paris, France, and the support of Prof. J.-C. Schwartz is gratefully acknowledged. We thank Drs. Joseph Gally and Nephi Stella for reading this manuscript critically, Dr. Emmanuelle di Tomaso for discussion, and Prof. S. Yamamoto, Prof. H. S. Hansen, and their colleagues for sharing results before publication.

Correspondence should be addressed to Daniele di Piomelli, The Neurosciences Institute, 10640 John J. Hopkins Drive, San Diego, CA 92121.

Dr. Gaillet's present address: Laboratoire de Neurobiologie et Endocrinologie, CNRS URA 1197, Montpellier, France.

Copyright $\odot 1996$ Society for Neuroscience $0270-6474 / 96 / 163934-09 \$ 05.00 / 0$
}

Marzo et al., 1994) and by enzymatic hydrolysis, catalyzed by a selective amidohydrolase activity (Desarnaud et al., 1995; Hillard et al., 1995; Ueda et al., 1995).

Two molecular mechanisms have been proposed for the generation of anandamide and other NAEs. The energy-independent condensation of ethanolamine and fatty acid has been reported (Colodzin et al., 1963; Deutsch and Chin, 1993; Devane and Axelrod, 1994; Kruszka and Gross, 1994). This reaction, which requires high concentrations of ethanolamine and fatty acid as well as alkaline $\mathrm{pH}$ optima, may be catalyzed by anandamide amidohydrolase acting in reverse (Ueda et al., 1995). Alternatively, anandamide and other NAEs may be produced by $\mathrm{Ca}^{2+}$-stimulated, phosphodiesterase-mediated cleavage of $\mathrm{N}$-acylphosphatidylethanolamine (NAPE), a biochemical pathway extensively studied by Schmid and collaborators before the discovery of anandamide (for review, see Schmid et al., 1990).

In the present study, we used rat cortical neurons in primary culture to address three questions relevant to the role of NAPE as precursor for NAEs. In which brain cell types does NAPE biosynthesis occur? Is NAPE biosynthesis regulated by neural activity or by stimulation of neurotransmitter receptors? What enzymatic mechanisms underlie NAPE biosynthesis? Our results indicate that NAPE is synthesized in neurons, not in astrocytes, and that NAPE biosynthesis is controlled by intracellular $\mathrm{Ca}^{2+}$ levels $\left(\left[\mathrm{Ca}^{2+}\right]_{i}\right)$. Rises in $\left[\mathrm{Ca}^{2+}\right]_{i}$ lead to the stimulation of an $\mathrm{N}$-acyltransferase activity that catalyzes the transfer of an acyl group from phosphatidylcholine (PC) to the ethanolamine moiety of phosphatidylethanolamine (PE), producing NAPE. Finally, our results show that NAPE biosynthesis is potentiated by agents that stimulate cAMP formation in neurons, including vasoactive intestinal peptide (VIP). 

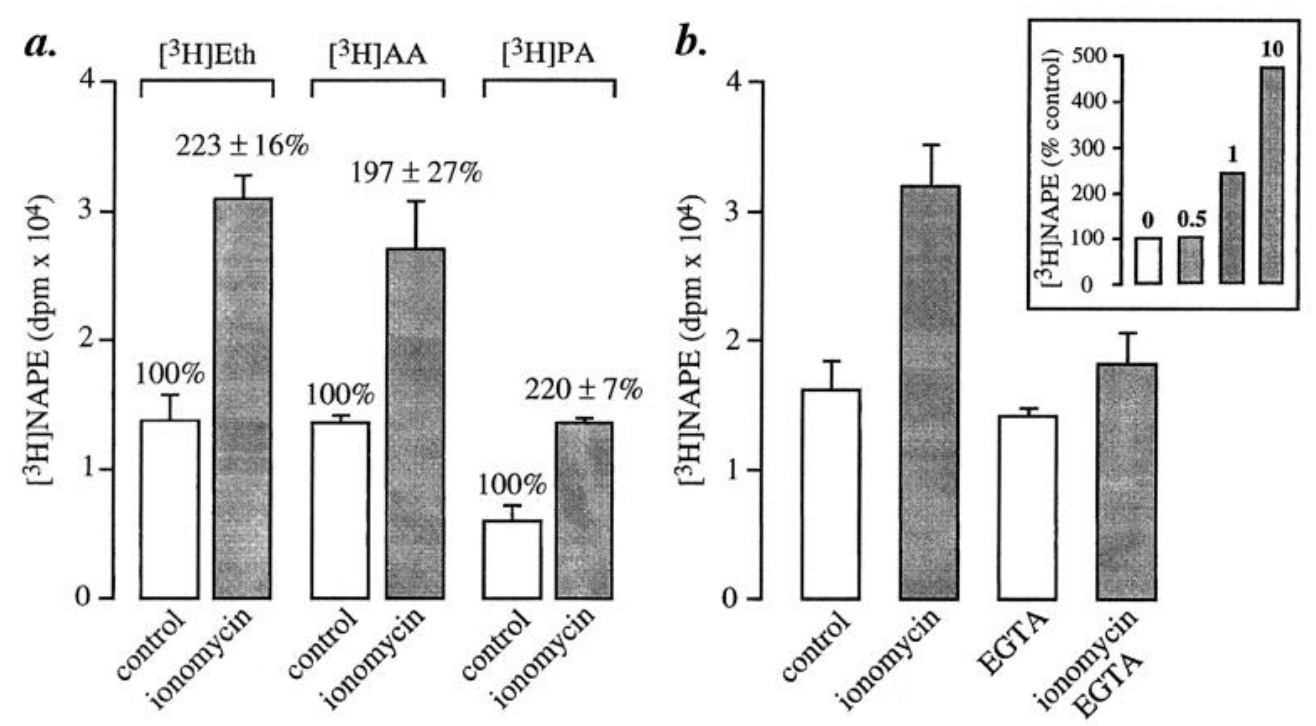

c.

d.
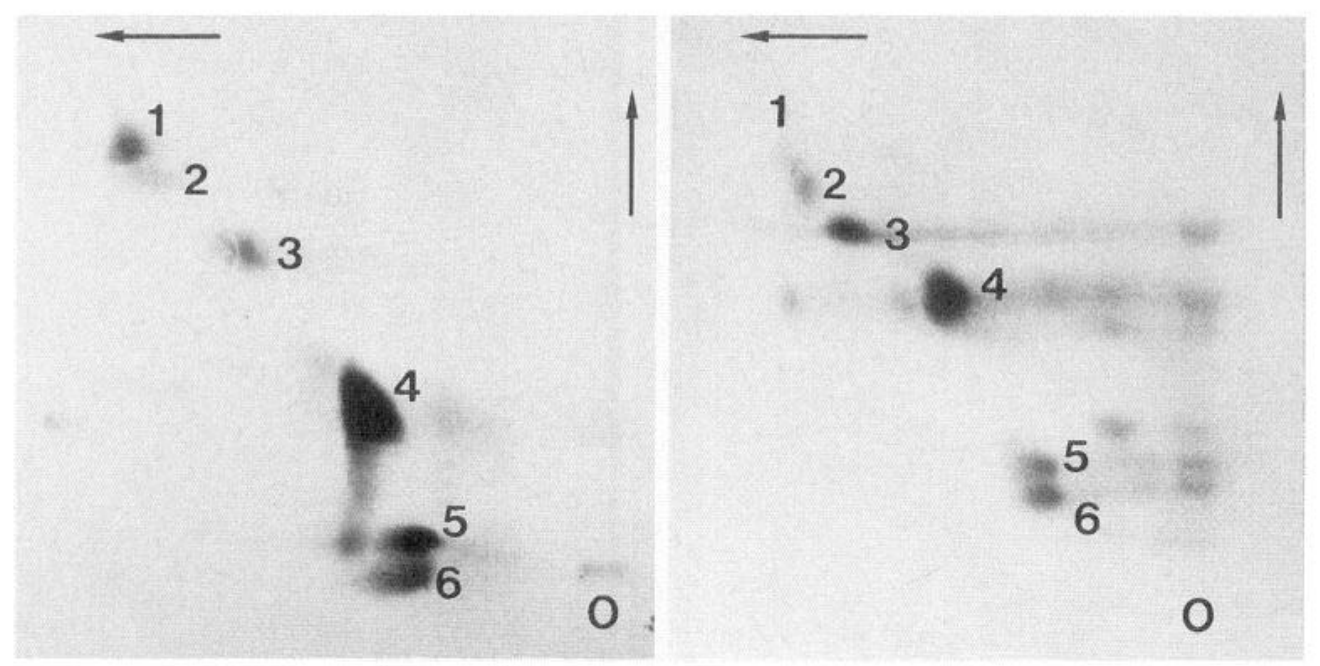

Figure 1. Biosynthesis of $\left[{ }^{3} \mathrm{H}\right] \mathrm{NAPE}$ in primary cultures of rat brain cortical neurons. $a$, Ionomycin $(1 \mu \mathrm{M}, 10 \mathrm{~min})$ stimulates $\left[{ }^{3} \mathrm{H}\right] \mathrm{NAPE}$ biosynthesis in neurons labeled by incubation with $\left[{ }^{3} \mathrm{H}\right]$ ethanolamine $(E t h),\left[{ }^{3} \mathrm{H}\right]$ arachidonic acid $(A A)$, or $\left[{ }^{3} \mathrm{H}\right]$ palmitic acid $(P A)$. NAPE was fractionated by column chromatography, and NAPE-containing fractions were analyzed by monodimensional TLC. Results are expressed as mean \pm SEM (dpm/dish) of six separate experiments. $b$, The effect of ionomycin is prevented by chelating extracellular $\mathrm{Ca}^{2+}$ with EGTA (10 mM) and is concentration-dependent (inset, $\mu \mathrm{M}$ concentrations). In these experiments, the neurons were labeled with $\left[{ }^{3} \mathrm{H}\right]$ ethanolamine. $c, d$, Ionomycin stimulates NAPE biosynthesis in neurons $(c)$, but not in astrocytes $(d)$. Cultures were labeled by overnight incubation with $\left[{ }^{14} \mathrm{C}\right]$ arachidonic acid. NAPE was analyzed by bidimensional TLC and autoradiography. On these representative chromatograms, the numbers indicate the positions of the following lipids: (1) NAPE; (2) unknown; (3) cerebrosides; (4) PE; (5) PC; (6) phosphatidylserine plus phosphatidylinositol. $O$, Origin.

\section{MATERIALS AND METHODS}

Materials. NAPE (1-palmitoyl,2-oleoyl-sn-glycerol-3-phosphoethanolamine$N$-arachidonoyl), PE, PC, sphingomyelin, and cerebrosides were obtained from Avanti Polar Lipids (Alabaster, AL); diacylglycerols, triacylglycerols, monoacylglycerols, cholesterol, and free fatty acids were from Nu-Chek Prep (Elysian, MN); calmidazolium, chelerythrine, 1,8-dideoxyforskolin, forskolin, $\mathrm{KN}-62$, and 4- $\beta$-phorbol-myristate-acetate were from Research Biochemicals (Natick, MA); ionomycin was from Boehringer Mannheim (Indianapolis, IN), and vasoactive intestinal peptide was from Calbiochem (La Jolla, CA); $\left[{ }^{3} \mathrm{H}\right]$ ethanolamine, $\left[{ }^{3} \mathrm{H}\right]$ arachidonic acid, $\left[{ }^{14} \mathrm{C}\right] \mathrm{ar}-$ achidonic acid, and $\left[{ }^{3} \mathrm{H}\right]$ palmitic acid were from Amersham (Arlington Heights, IL); $\left[{ }^{3} \mathrm{H}\right]$ oleic acid and $\left[{ }^{14} \mathrm{C}\right]$ oleoyl-coenzyme A were from American Radiolabeled Products (St. Louis, MO); all other chemicals were from Sigma (St. Louis, MO). Cyclosporine was a generous gift of Sandoz Pharma (Basel, Switzerland).

Cell cultures and incubations. Cortical neuron and astrocyte cultures were prepared from 17-d-old rat embryos and maintained in serumsupplemented culture medium, as described previously (Di Marzo et al.,
1994). Cortical neurons were used after 5-6 d in vitro. Neurons (90 mm dishes, plated at a density of $2.5 \times 10^{7}$ cells/dish) and astrocyte cultures ( $90 \mathrm{~mm}$ dishes, used at confluence) were labeled by incubation $(16-20 \mathrm{hr}$ ) with $\left[{ }^{3} \mathrm{H}\right]$ ethanolamine $(1 \mu \mathrm{Ci} / \mathrm{ml}, 34 \mathrm{Ci} / \mathrm{mmol}),\left[{ }^{3} \mathrm{H}\right]$ arachidonic acid $(1$ $\mu \mathrm{Ci} / \mathrm{ml}, 40-60 \mathrm{Ci} / \mathrm{mmol}),\left[{ }^{14} \mathrm{C}\right]$ arachidonic acid $(1 \mu \mathrm{Ci} / \mathrm{ml}, 58 \mathrm{mCi} /$ $\mathrm{mmol})$, or $\left[{ }^{3} \mathrm{H}\right]$ palmitic acid $(1 \mu \mathrm{Ci} / \mathrm{ml}, 40-60 \mathrm{Ci} / \mathrm{mmol})$. The cultures were rinsed with DMEM (Gibco, Grand Island, NY) and incubated for various times (10 $\mathrm{min}$ in typical experiments) in DMEM $(5 \mathrm{ml})$ containing drugs at the indicated concentrations. Incubations were stopped by adding ice-cold methanol $(2 \mathrm{ml})$.

Lipid extraction and analyses. The methanol-containing samples were extracted with chloroform $(2 \mathrm{ml})$, and the chloroform extracts were subjected to open-bed chromatography on $1 \mathrm{ml}$ silica gel G-columns. The NAPE-containing fractions [eluted with chloroform/methanol, 6:4 (v/v)] were analyzed by thin-layer chromatography (TLC, Analtech) using a solvent system of chloroform/methanol/ammonium hydroxide (80:20:1). In some experiments, bands $(1 \mathrm{~cm})$ were cut and radioactivity was measured by liquid scintillation counting. In other experiments, the 
a.

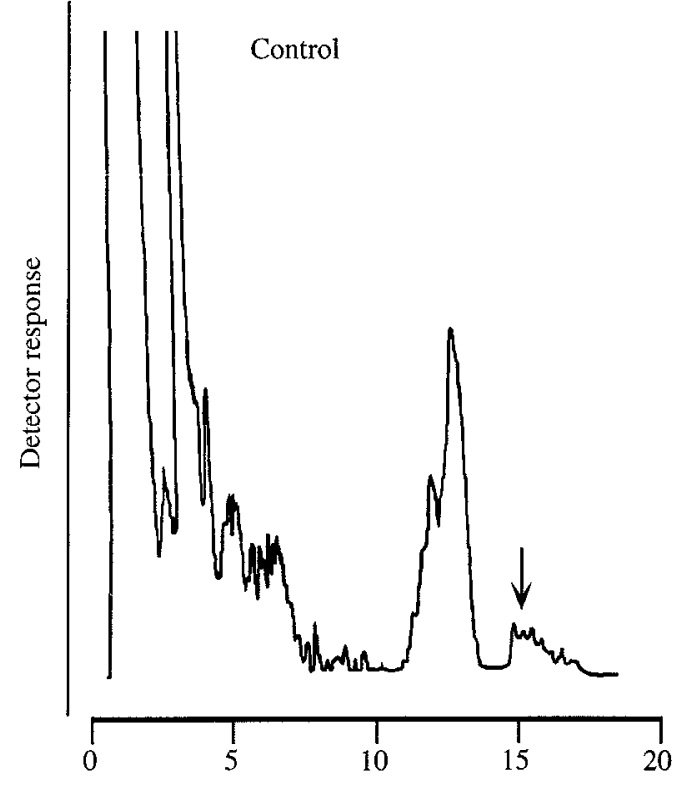

b.

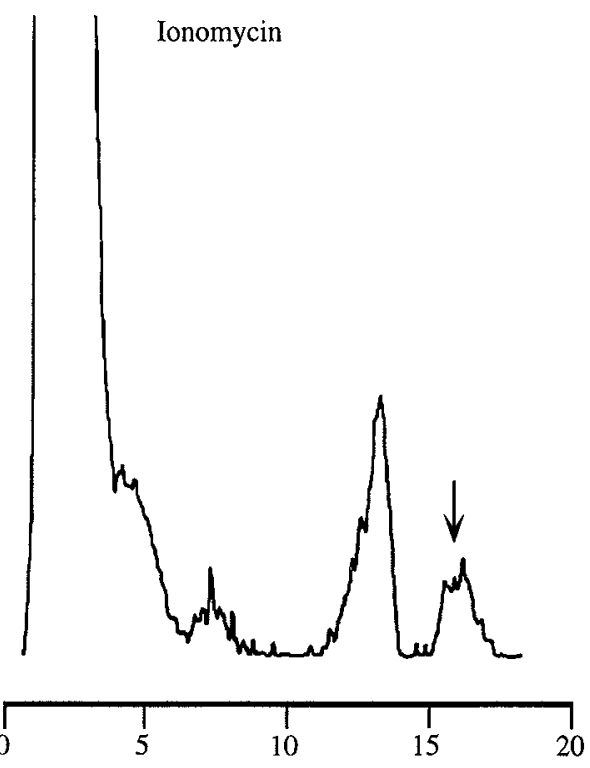

Retention time (min)

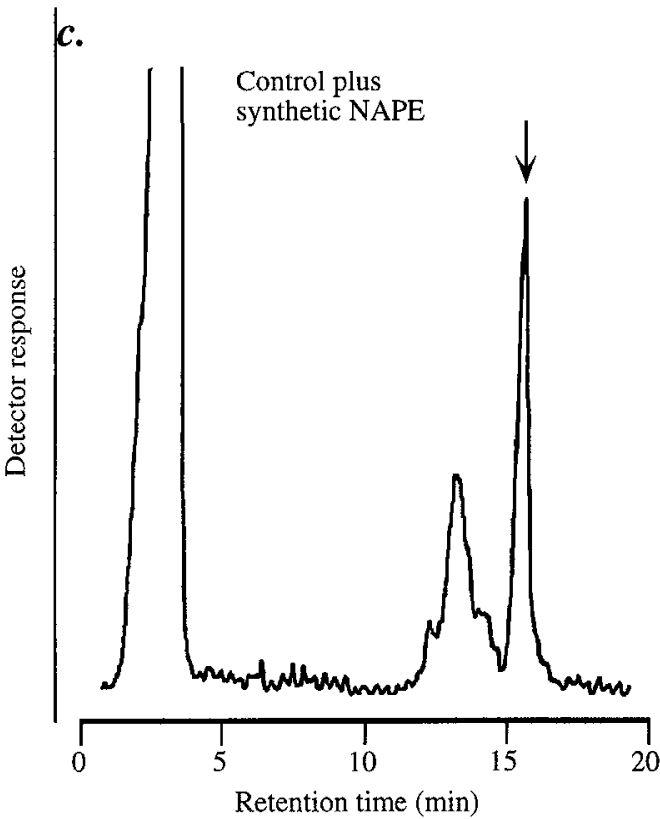

d.

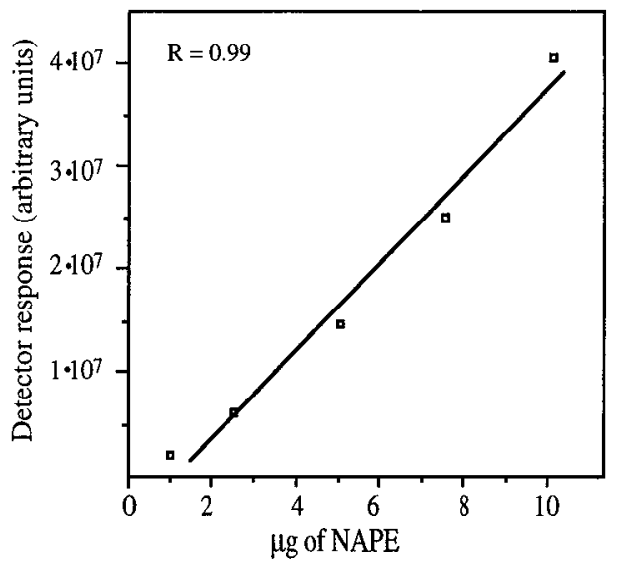

Figure 2. Quantitative analysis of neuronal NAPE by HPLC coupled to evaporative light-scaltering detection. Representative chromatogranı from (a) control neurons, $(b) 1 \mu \mathrm{M}$ ionomycin-stimulated neurons, and $(c)$ control neurons to which synthetic NAPE $(10 \mu \mathrm{g})$ was added before extraction, to verify its HPLC coelution with native NAPE. The arrows indicate the retention time of synthetic NAPE. Lipids were extracted and fractionated by column chromatography. The NAPE-containing fractions from two culture dishes were pooled and subjected to reversed-phase HPLC, as described in Materials and Methods. $d$, Response of the light-scattering detector as a function of injected synthetic NAPE (in $40 \mu 1$ of chloroform). Photomultiplier voltage was set at $800 \mathrm{~V}$, and nebulization temperature was set at $90^{\circ} \mathrm{C}$.

radioactive lipids were fractionated by bidimensional TLC (system 1 : chloroform/methanol/ammonium hydroxide/water, 65:25:4:1; system 2 : chloroform/acetone/methanol/acetic acid/water, 30:40:10:7:5), visualized by autoradiography (Kodak XAR-5 film, 7 d exposure), and identified by comigration with authentic standards [visualized by spraying the plates with a solution of phosphomolybdic acid in ethanol, $10 \%(\mathrm{w} / \mathrm{v})]$. For quantitative analyses, NAPE-containing fractions obtained by open-bed column chromatography were subjected to further purification by reversed-phase HPLC on a $\mu$ Bondapak C18 column (Waters, Milford, MA) using a gradient of water in methanol (from 30 to $0 \%$ over $10 \mathrm{~min}$ ). This HPLC system allowed us to resolve NAPE (retention time, $\sim 14$ min) from the following lipid components, which may be present in the NAPE-containing fractions: PE, PC, sphingomyelin, cerebrosides, diacylglycerols, triacylglycerols, monoacylglycerols, and cholesterol. NAPE differing in the $N$-acyl group were not resolved. The HPLC column was connected to an evaporative light-scattering detector (Eurosep) (for review, see Christie, 1987) with photomultiplier voltage set at $800 \mathrm{~V}$ and nebulization temperature set at $90^{\circ} \mathrm{C}$. Under these conditions, we found that the photomultiplier response was linear between 1 and $10 \mu \mathrm{g}$ of injected synthetic NAPE (Fig. $2 d$ ). Each HPLC analysis was carried out on pooled extracts from two dishes of neuronal cultures. In some experiments, the NAE-containing fractions from open-bed chromatography 

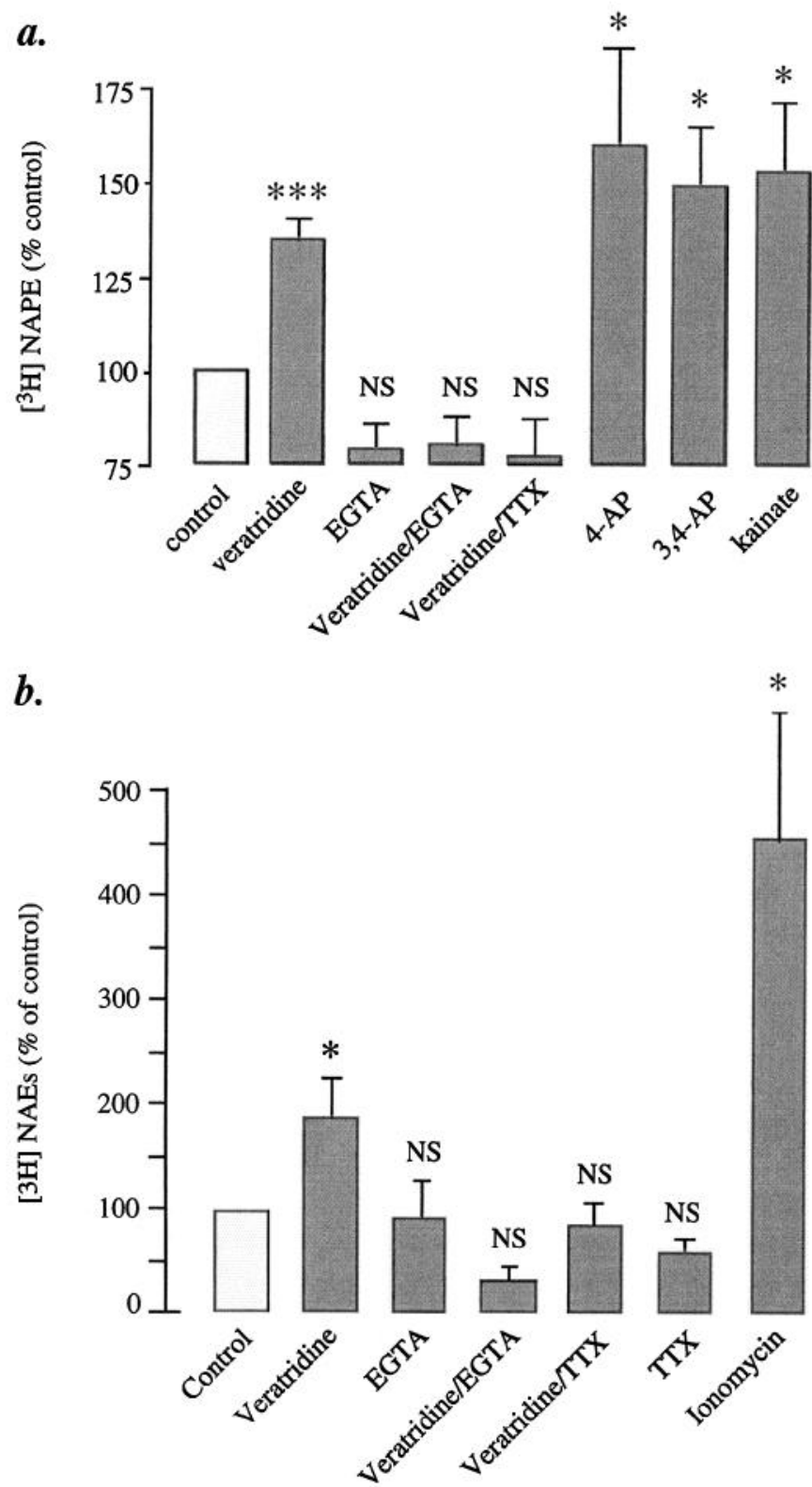

Figure 3. Effects of various depolarizing agents on $\left[{ }^{3} \mathrm{H}\right] \mathrm{NAPE}$ biosynthesis and $\left[{ }^{3} \mathrm{H}\right]$ NAE formation in cortical neurons. $a,\left[{ }^{3} \mathrm{H}\right]$ NAPE biosynthesis: veratridine $(20 \mu \mathrm{M}), 4$-aminopyridine $(4-A P ; 3 \mathrm{mM}), 3,4$-diaminopyridine $(3,4-A P ; 3 \mathrm{~mm})$, and kainate $(0.1 \mathrm{~mm})$. EGTA and tetrodotoxin (TTX) were used at $10 \mathrm{~mm}$ and $1 \mu \mathrm{M}$, respectively. $b,\left[{ }^{3} \mathrm{H}\right] \mathrm{NAE}$ formation was determined in the same or parallel experiments. The ability of 4-AP, 3,4-AP, and kainate to stimulate $\left[{ }^{3} \mathrm{H}\right] \mathrm{NAE}$ formation was documented previously (Di Marzo et al., 1994). The effect of ionomycin (1 $\mu \mathrm{M}, 10 \mathrm{~min})$ is shown for comparison. Results are expressed as percent of control and represent the mean \pm SEM of five to eight separate experiments; * $p<$ $0.05,{ }^{* * *} p<0.001$ (ANOVA); $N S$, nonsignificantly different from unstimulated cultures.

(eluted with chloroform/methanol, 9:1) were analyzed by normal-phase HPLC on a Resolve silica column (Waters) using a gradient of isopropanol in $n$-hexane (from 0 to $20 \%$ over $20 \mathrm{~min}$ ). All NAEs were eluted from the column at a retention time of $\sim 12 \mathrm{~min}$. One minute fractions were collected during elution, and radioactivity was determined by liquid scintillation counting.

NAPE biosynthesis in neuronal homogenates. $N$-acyltransferase assays

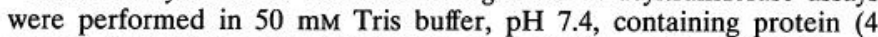
$\mathrm{mg} / \mathrm{ml}$ ), $0.1 \%$ Triton X-100 (TX-100), $3 \mathrm{mM} \mathrm{CaCl}$, or $10 \mathrm{~mm}$ EGTA and $\left[{ }^{14} \mathrm{C}\right]$ dioleoyl-PC or $\left[{ }^{14} \mathrm{C}\right]$ dipalmitoyl-PC $(1 \mu \mathrm{Ci} / \mathrm{ml}, 80-120 \mathrm{mCi} / \mathrm{mmol})$.
After $1 \mathrm{hr}$ of incubation, reactions were stopped with methanol and the lipid was extracted. The samples were applied to silica gel G-columns, $\left[{ }^{14} \mathrm{C}\right]$ NAPE-containing fractions were eluted with chloroform/methanol (6:4), and radioactivity in the fractions was measured by liquid scintillation counting. Unreacted $\left[{ }^{14} \mathrm{C}\right] \mathrm{PC}$ was eluted with $100 \%$ methanol. In initial experiments, we confirmed the identity of the radioactive material eluting from the silica gel G-columns as $\left[{ }^{14} \mathrm{C}\right]$ NAPE by bidimensional TLC as described above (data not shown). Incubations with $\left[{ }^{3} \mathrm{H}\right]$ oleic acid $(60 \mathrm{Ci} / \mathrm{mmol})$ and $\left[{ }^{14} \mathrm{C}\right]$ oleoyl-coenzyme $\mathrm{A}(55 \mathrm{mCi} / \mathrm{mmol})$ were carried

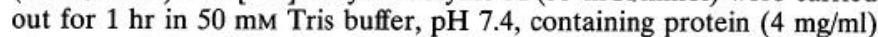
plus one or a combination of the following: $3 \mathrm{~mm} \mathrm{CaCl}_{2}, 10 \mathrm{~mm}$ EGTA, and $0.1 \% \mathrm{TX}-100$. After extraction, the radioactive lipids were fractionated on silica gel G-columns and analyzed by monodimensional TLC, as described above.

Intracellular $\left[\mathrm{Ca}^{2+}\right]_{i}$ and cAMP measurements. Intracellular $\left[\mathrm{Ca}^{2+}\right]_{\mathrm{i}}$ measurements were performed by dual-emission microfluorimetry using the fluorescent dye Indo $1-\mathrm{AM}$, and $\left[\mathrm{Ca}^{2+}\right]_{i}$ concentrations were calculated from the fluorescence ratio (measured at 410 and $480 \mathrm{~nm}$ ) using a $K_{\mathrm{d}}$ of $250 \mathrm{nM}$ for Indo 1-AM (Grynkiewicz et al., 1985; Venance et al., 1995). cAMP was measured by ELISA using a commercial kit (Amersham) and following the manufacturer's instructions.

Statistical analyses. Results are expressed as the mean \pm SEM of $n$ experiments, and statistical significance was determined by ANOVA.

\section{RESULTS}

The $\mathrm{Ca}^{2+}$ ionophore ionomycin is potent in increasing $\left[{ }^{3} \mathrm{H}\right]$ NAPE levels in primary cultures of rat cortical neurons labeled to apparent isotopic equilibrium with $\left[{ }^{3} \mathrm{H}\right]$ ethanolamine (Fig. $1 a$ ). This effect is (1) dependent on the presence of extracellular $\mathrm{Ca}^{2+}$ ions, as shown by the ability of EGTA (10 mM) to prevent it (Fig. $1 b$ ); (2) dependent on the concentration of ionomycin (Fig. 1b, inset); (3) restricted to neurons: NAPE is prominently labeled in ionomycin-stimulated neurons (Fig. 1c), whereas only background radioactivity comigrates with NAPE in ionomycin-stimulated astrocytes (Fig. 1 d); (4) time-dependent and significant after a 4 min incubation with ionomycin (data not shown). Under identical conditions, ionomycin $(1 \mu \mathrm{M})$ stimulates $\left[{ }^{3} \mathrm{H}\right]$ NAE formation in cortical and striatal neurons (Di Marzo et al., 1994).

The observed increase in $\left[{ }^{3} \mathrm{H}\right]$ ethanolamine-labeled NAPE may reflect either a de novo biosynthesis of the phospholipid or an increased turnover in its ethanolamine-containing moiety, expected from the stimulation of a D-type phosphodiesterase activity (Di Marzo et al., 1994). Two findings support the possibility that de novo biosynthesis contributes to the observed effect. First, ionomycin produces equivalent effects in neurons labeled with two additional radioactive NAPE precursors, $\left[{ }^{3} \mathrm{H}\right]$ palmitic acid and $\left[{ }^{3} \mathrm{H}\right]$ arachidonic acid, which are expected to be preferentially incorporated into distinct moieties of NAPE $\left(\left[{ }^{3} \mathrm{H}\right]\right.$ palmitic acid into the $s n-1$ position, and $\left[{ }^{3} \mathrm{H}\right]$ arachidonic acid into the $s n-2$

Table 1. Effects of various pharmacological agents on $\left[{ }^{3} \mathrm{H}\right]$ NAPE formation in cortical neurons in primary culture

\begin{tabular}{lcl} 
Drug & $\begin{array}{l}\text { Concentration } \\
(\mu \mathrm{M})\end{array}$ & $\begin{array}{l}{\left[{ }^{3} \mathrm{H}\right] \mathrm{NAPE}(\% \text { of }} \\
\text { control } \pm \text { SEM })\end{array}$ \\
\hline Ionomycin & 1 & 100 \\
+ Calmidazolium & 200 & $112 \pm 3 \quad(n=3)$ \\
+ KN-62 & 10 & $104 \pm 28(n=12)$ \\
+ Cyclosporin & 200 & $150 \pm 15(n=6)$ \\
+ PMA & 1 & $99 \pm 10(n=3)$ \\
+ Chelerythrin & 5 & $71 \pm 5(n=6)$ \\
PMA alone & 1 & $101 \pm 6(n=11)$
\end{tabular}

Assays were carried out as described in Materials and Methods. Kinase and phosphatase inhibitors were added to the incubation media $10-15$ min before stimulation. In the presence of ionomycin $(1 \mu \mathrm{M})$, radioactivity in $\left[{ }^{3} \mathrm{H}\right] \mathrm{NAPE}$ was $17,100 \pm 2116$ dpm/dish $(n=20)$. 


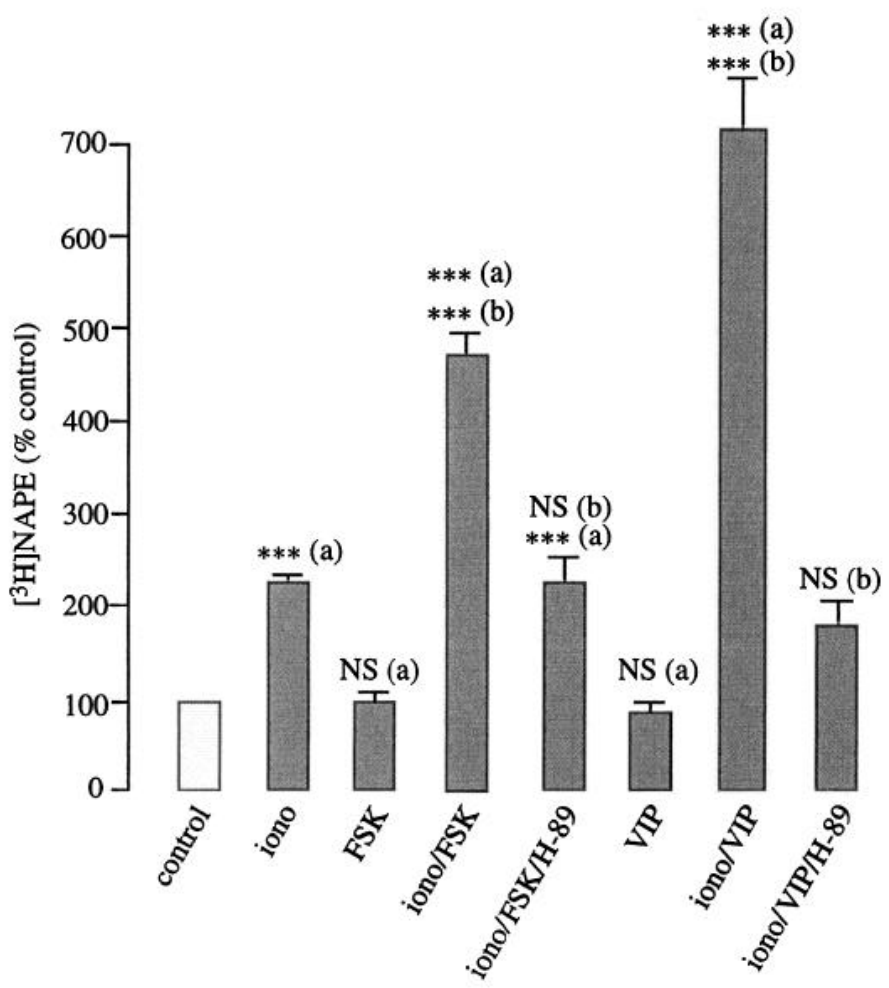

Figure 4. Potentiation of ionomycin (iono)-stimulated $\left[{ }^{3} \mathrm{H}\right] \mathrm{NAPE}$ biosynthesis by forskolin $(F S K ; 10 \mu \mathrm{M})$ and vasoactive intestinal peptide $(V I P ; 1$ $\mu \mathrm{M})$ in cortical neurons. ${ }^{* * *} p<0.001 ; a$, versus control; $b$, versus ionomycin; $N S$, nonsignificant.

position; Fig. 1a). Second, mass analysis of NAPE by HPLC coupled to light-scattering detection reveals that neurons contain $0.77 \pm 0.13 \mu \mathrm{g}$ of NAPE/dish when unstimulated, and $1.4 \pm 0.2$ $\mu \mathrm{g} / \mathrm{dish}$ when stimulated with ionomycin $(n=4$; Fig. $2 a, b)$. The HPLC fractionation used here provides both a reliable method for identifying unlabeled NAPE (Fig. $2 c$ and Materials and Methods) and a sensitive approach to the quantification of this lipid in the mass range present in cultured neurons (Fig. $2 d$ ).

We determined the $\left[\mathrm{Ca}^{2+}\right]_{i}$ at which ionomycin stimulates

Table 2. NAPE biosynthesis in homogenates of neuronal cultures: lack of incorporation of labeled fatty acids or oleoyl $\mathrm{CoA}$

\begin{tabular}{llll} 
Conditions & $\begin{array}{l}{\left[{ }^{14} \mathrm{C}\right] \text { palmitic acid }} \\
\mathrm{n}=3)\end{array}$ & $\begin{array}{l}{\left[{ }^{3} \mathrm{H}\right] \text { oleic acid }} \\
(\mathrm{dpm} ; n=2)\end{array}$ & $\begin{array}{l}{\left[{ }^{14} \mathrm{C}\right] \text { oleoyl CoA }} \\
(\mathrm{dpm} ; n=2)\end{array}$ \\
\hline Tissue & $864 \pm 149$ & $\mathrm{ND}$ & $\mathrm{ND}$ \\
Boiled tissue & $790 \pm 184$ & 375 & 90 \\
$+\mathrm{Ca}^{2+}$ & $528 \pm 57$ & 452 & 87 \\
$+\mathrm{EGTA}$ & $\mathrm{ND}$ & 297 & 38 \\
$+\mathrm{TX}-100$ & $477 \pm 66$ & $\mathrm{ND}$ & $\mathrm{ND}$ \\
$+\mathrm{Ca}^{2+}$ & & & \\
$\quad$ TX-100 & $358 \pm 11$ & ND & ND \\
$+\mathrm{Ca}^{2+}$, & & & \\
$\quad$ TX-100, & & & \\
EGTA & $543 \pm 11$ & ND & ND
\end{tabular}

Homogenates were incubated for $1 \mathrm{~h}$ at $37^{\circ} \mathrm{C}$ in $50 \mathrm{~mm}$ Tris, $\mathrm{pH} 7.4$, containing one or more of the following: $\mathrm{Ca}^{2+}(3 \mathrm{~mm})$, EGTA $(10 \mathrm{~mm})$, TX-100 $(0.1 \%, \mathrm{v} / \mathrm{v})$. Results are from one experiment, representative of two experiments performed in triplicate with $\left[{ }^{14} \mathrm{C}\right]$ palmitic acid, and from two experiments with $\left[{ }^{3} \mathrm{H}\right]$ oleic acid and $\left[{ }^{14} \mathrm{C}\right] \mathrm{o}-$ leoyl $\mathrm{CoA}$.
NAPE biosynthesis by using the $\mathrm{Ca}^{2+}$-sensitive dye Indo 1-AM. Ionomycin $(1 \mu \mathrm{M})$ evokes in $\sim 30 \%$ of the neurons a slow oscillatory rise in $\left[\mathrm{Ca}^{2+}\right]_{\mathrm{i}}$ (data not shown). In responding neurons $(51 / 170),\left[\mathrm{Ca}^{2+}\right]_{\mathrm{i}}$ increases on average from a basal level of $35 \pm$ 4 to $154 \pm 16 \mathrm{~nm}$ after a $10 \mathrm{~min}$ incubation with ionomycin. Such $\left[\mathrm{Ca}^{2+}\right]_{\mathrm{i}}$ responses, well within those caused by neuronal activity, prompted us to study the effects of membrane-depolarizing agents on NAPE biosynthesis.

Application of the $\mathrm{Na}^{+}$-channel activator veratridine $(20 \mu \mathrm{M})$ produces in $81 \%$ of the neurons a $\left[\mathrm{Ca}^{2+}\right]_{\mathrm{i}}$ rise (basal, $40 \pm 1 \mathrm{nM}$; $20 \mathrm{sec}, 255 \pm 11 \mathrm{~nm} ; 10 \mathrm{~min}, 120 \pm 1 \mathrm{~nm} ; n=183$ ). In identical experiments, veratridine produced a significant increase in $\left[{ }^{3} \mathrm{H}\right]$ NAPE biosynthesis (Fig. $3 a$ ). The latter is prevented by EGTA $(10 \mathrm{~mm})$ or tetrodotoxin $(1 \mu \mathrm{M})$, confirming the participation of extracellular $\mathrm{Ca}^{2+}$ and $\mathrm{Na}^{+}$channels, respectively (Fig. $3 a$ ). We observed similar increases in $\left[{ }^{3} \mathrm{H}\right]$ NAPE with two $\mathrm{K}^{+}$channel blockers (4-aminopyridine and 3,4-diaminopyridine, both at $3 \mathrm{mM}$ ) and with a glutamate-receptor agonist (kainate, $0.1 \mathrm{~mm}$; Fig. $3 a$ ). In the same experiments, we also measured $\left[{ }^{3} \mathrm{H}\right] \mathrm{NAE}$ formation and found that it was enhanced (Fig. $3 b$ ), as expected from previous results (Di Marzo et al., 1994; Hansen et al., 1995). It should be noted that ionomycin is more efficacious than veratridine in enhancing NAPE biosynthesis, although it produces a smaller effect on $\left[\mathrm{Ca}^{2+}\right]_{\mathrm{i}}$ : differences in the kinetics or subcellular localization of the $\left[\mathrm{Ca}^{2+}\right]_{\mathrm{i}}$ changes evoked by the two drugs might account for this discrepancy.

Many neuronal actions of $\mathrm{Ca}^{2+}$ are mediated by stimulation of $\mathrm{Ca}^{2+} /$ calmodulin-dependent protein kinases and phosphatases (Walaas and Greengard, 1987; Hanson and Schulman, 1992). We found, however, that inhibiting calmodulin with calmidazolium $(200 \mu \mathrm{M}), \mathrm{Ca}^{2+} /$ calmodulin-dependent protein kinase II with $\mathrm{KN}-62(10 \mu \mathrm{M})$, or calcineurin with cyclosporine $(200 \mu \mathrm{M})$ did not affect ionomycin-induced $\left[{ }^{3} \mathrm{H}\right] \mathrm{NAPE}$ biosynthesis (Table 1). Protein kinase $\mathrm{C}(\mathrm{PKC})$ is also unlikely to be involved, because the PKC activator 4- $\beta$-phorbol-myristate acetate (PMA, $1 \mu \mathrm{M}$ ) neither mimics nor potentiates the effect of ionomycin, and the PKC blocker chelerythrine inhibits it only partially even when used at a supramaximal concentration ( $5 \mu \mathrm{M}$; Table 1$)$.

In contrast with PMA, the adenylyl cyclase activator forskolin $(10 \mu \mathrm{M})$ is potent in enhancing ionomycin-induced $\left[{ }^{3} \mathrm{H}\right]$ NAPE accumulation (Fig. 4). Pharmacological experiments indicate that this response is mediated by cAMP: the potentiating effect of forskolin is not mimicked by the inactive forskolin analog 1,8 dideoxyforskolin $(10 \mu \mathrm{M}$; data not shown) and is prevented by the selective cAMP-dependent protein kinase inhibitor $\mathrm{H}-89(0.5 \mu \mathrm{M}$; Fig. 4). When applied alone, forskolin has no effect on $\left[{ }^{3} \mathrm{H}\right] \mathrm{NAPE}$ levels (Fig. 4).

The neuroactive peptide VIP is thought to acts as a neuronal messenger in mammalian cortex (Giachetti et al., 1977; Quick et al., 1978; Magistretti and Morrison, 1988). VIP binds to VIP-type and to pituitary adenylyl-cyclase activating peptide (PACAP)-type receptors, which are both positively coupled to adenylyl cyclase activity (Ishihara et al., 1992; Hashimoto et al., 1993). We found that application of VIP $(1 \mu \mathrm{M})$ enhances ionomycin-evoked $\left[{ }^{3} \mathrm{H}\right]$ NAPE biosynthesis (Fig. 4). This effect is (1) half-maximal at $400 \pm 42 \mathrm{~nm}$ VIP $(n=2) ;(2)$ accompanied by increased cAMP levels (half-maximal at $300 \pm 53 \mathrm{~nm}$ VIP; $n=6$; data not shown); (3) prevented by inhibiting cAMP-dependent protein kinase activity with H-89 (Fig. 4). Like forskolin, VIP has no effect on $\left[{ }^{3} \mathrm{H}\right]$ NAPE levels when applied alone (Fig. 4). Importantly, VIP also potentiated ionomycin-evoked formation of $\left[{ }^{3} \mathrm{H}\right]$ NAEs. In three experiments, cortical neurons produced $145 \pm 12 \mathrm{dpm} / \mathrm{dish}$ 


\section{a. Calcium (3 mM)}
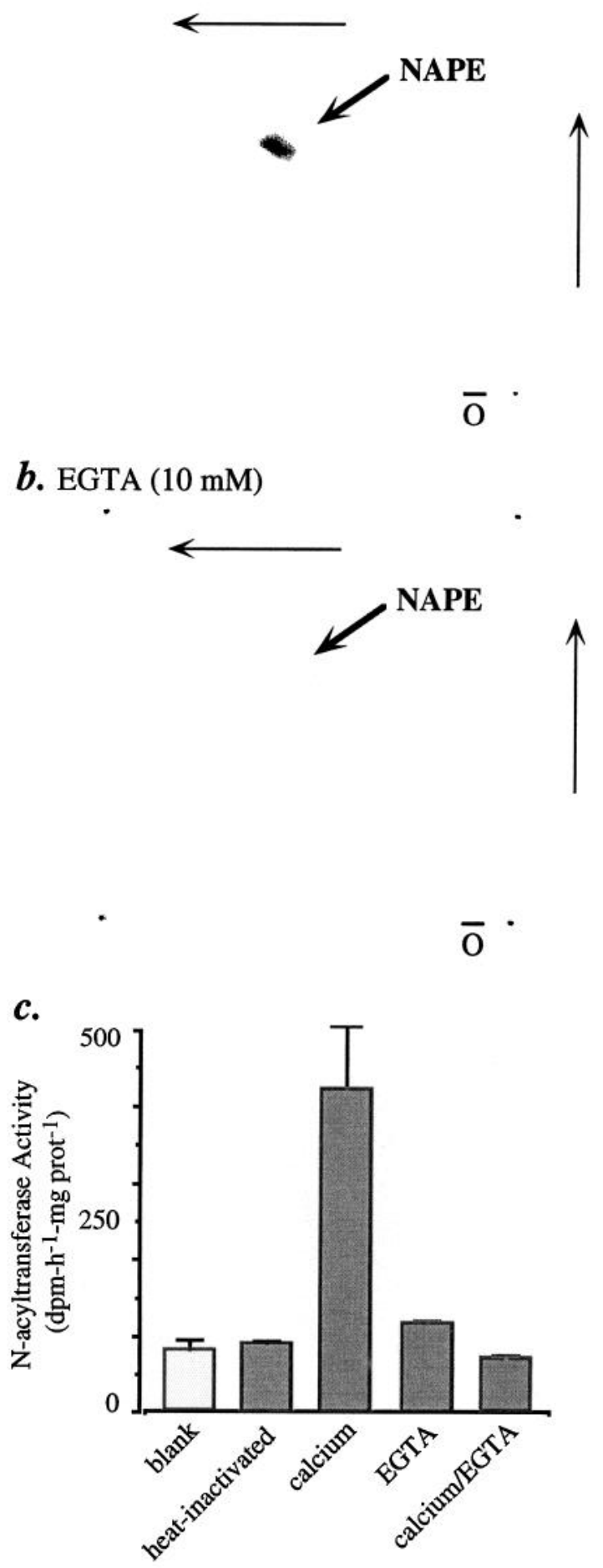

Figure 5. $\mathrm{Ca}^{2+}$-dependent $\left[{ }^{14} \mathrm{C}\right] \mathrm{NAPE}$ formation and $\mathrm{N}$-acyltransferase activity in homogenates of cortical neurons. Homogenates were incubated with $\left[{ }^{14} \mathrm{C}\right]$ dioleoyl-PC or $\left[{ }^{14} \mathrm{C}\right]$ dipalmitoyl-PC in the presence of either $\mathrm{Ca}^{2+}(3 \mathrm{mM})(a)$ or $10 \mathrm{~mm}$ EGTA $(b)$. The incubation mixtures were subjected to lipid extraction and analyzed by bidimensional TLC. Radioactivity on the plates was visualized with a PhosphorImager. $c$, $\mathrm{N}$-acyltransferase activity in neuron homogenates. Assay conditions and analysis by column chromatography are described in Materials and Methods. Results (mean \pm SEM) are from one experiment, performed in triplicate and typical of four experiments. of $\left[{ }^{3} \mathrm{H}\right] \mathrm{NAEs}$ under control conditions, $290 \pm 14 \mathrm{dpm} / \mathrm{dish}$ with ionomycin $(1 \mu \mathrm{M}), 223 \pm 47 \mathrm{dpm} / \mathrm{dish}$ with VIP alone $(1 \mu \mathrm{M})$, and $510 \pm 90 \mathrm{dpm} /$ dish with VIP plus ionomycin.

VIP-containing neurons in the cortex are also thought to secrete acetylcholine (Magistretti and Morrison, 1988). However, carbachol (1 mM), a cholinergic-receptor agonist, has no effect on the levels of $\left[{ }^{3} \mathrm{H}\right] \mathrm{NAPE}$ or $\left[{ }^{3} \mathrm{H}\right]$ NAEs when applied either alone or in combination with $1 \mu \mathrm{M}$ ionomycin (data not shown).

Experimental evidence suggests that NAPE may be produced by enzymatic N-acylation of PE (Hazlewood and Dawson, 1975; Schmid et al., 1990; Chapman and Moore, 1993). Two possible acyl group donors have been postulated to participate in this reaction: glycerophospholipids, in bacteria and animal tissues (Hazlewood and Dawson, 1975; Schmid et al., 1990), and free fatty acids, in plant tissues (Chapman and Moore, 1993). Another acyl donor, fatty acyl-coenzyme A, participates in the $\mathrm{N}$-acylation of sphinganine to $N$-acylsphinganine, a key step in the pathway of ceramide biosynthesis (Kishimoto, 1983). Homogenates of cortical neurons produce $\left[{ }^{14} \mathrm{C}\right] \mathrm{NAPE}$ when they are incubated in the presence of $\left[{ }^{14} \mathrm{C}\right] \mathrm{PC}$ and $\mathrm{Ca}^{2+}(3 \mathrm{~mm}$; Fig. $5 a)$, whereas we observed no $\left[{ }^{14} \mathrm{C}\right]$ NAPE synthesis in neuron homogenates incubated with EGTA (10 mM; Fig. $5 b$ ), or in astrocyte homogenates incubated with $3 \mathrm{mM} \mathrm{Ca}^{2+}$ (data not shown). By using an assay based on open-bed chromatography, we confirmed that $\left[{ }^{14} \mathrm{C}\right] \mathrm{NAPE}$ formation is calcium-dependent and, as expected of an enzymatic mechanism, sensitive to heating (Fig. $5 c$ ). In contrast with the results obtained with $\left[{ }^{14} \mathrm{C}\right] \mathrm{PC}$, we found that neither $\left[{ }^{14} \mathrm{C}\right]$ oleoyl-coenzyme A nor $\left[{ }^{3} \mathrm{H}\right]$ oleic acid or $\left[{ }^{14} \mathrm{C}\right]$ palmitic acid is incorporated into NAPE under various experimental conditions (Table 2).

\section{DISCUSSION}

A possible biochemical mechanism for the formation of biologically active NAEs, including anandamide, is the hydrolytic cleavage of the phospholipid precursor NAPE, a minor N-acylated derivative of PE. This mechanism, illustrated schematically in Figure 6, postulates that stimulus-dependent rises in $\left[\mathrm{Ca}^{2+}\right]_{\mathrm{i}}$ activate a D-type phosphodiesterase activity (phospholipase D) that catalyzes NAPE hydrolysis. Because NAPE is composed of multiple molecular species differing in the fatty acyl moiety linked to $\mathrm{PE}$, the phosphodiesterase reaction results in the mobilization of a family of different NAEs. We do not fully understand yet the biological roles of this heterogeneous family of lipid molecules. We know, however, that several NAEs share the ability to bind to and activate cannabinoid receptors: in brain and in peripheral tissues, anandamide and other polyunsaturated NAEs activate CB1-type receptors (for review, see Mechoulam et al., 1994), whereas in mastocytes and in mastocyte-derived cell lines, $\mathrm{N}$-palmitoylethanolamine activates a CB2-like receptor subtype (Facci et al., 1995). Such pleiotropic properties of the NAEs are reminiscent of another lipid-signaling family, the eicosanoids, which are generated from a single precursor molecule, arachidonic acid, and activate multiple transmembrane receptors (for review, see Piomelli, 1994).

Several lines of evidence support the biochemical mechanism of NAE formation illustrated in Figure 6. The spectrum of NAEs recovered after stimulation of neurons in primary culture closely corresponds to that expected from the $N$-acyl moiety composition of neuronal NAPE. Further, stimulus-dependent formation of NAEs is accompanied by increased NAPE turnover. Even further, neuron homogenates contain an enzymatic activity that catalyzes the hydrolysis of radiolabeled NAPE, producing anandamide and 


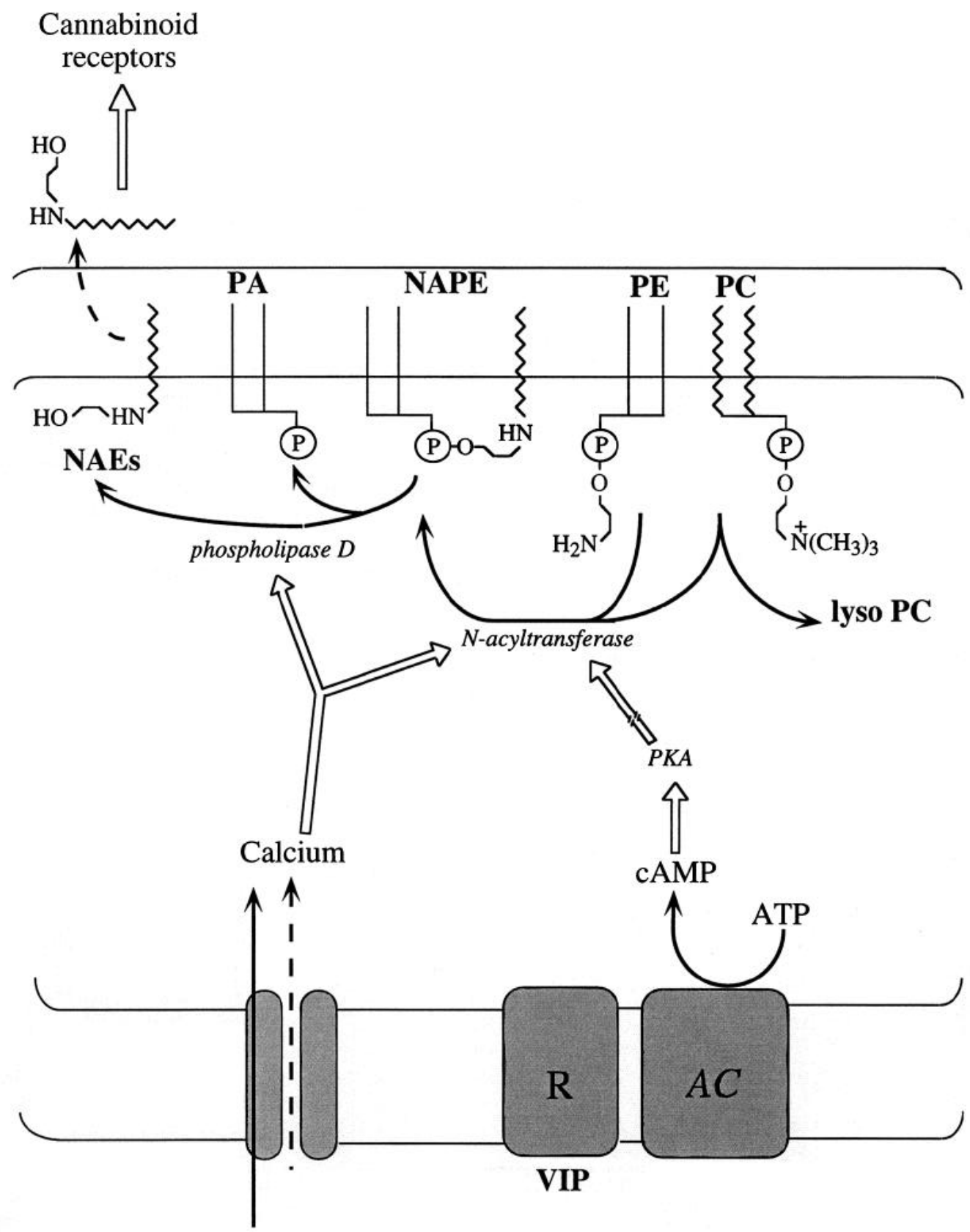

Figure 6. Model of biosynthesis and regulation of the endogenous cannabinoid precursor NAPE in rat cortical neurons. $\left[\mathrm{Ca}^{2+}\right]_{\mathrm{i}}$ rises produced by neuronal depolarization may stimulate an $\mathrm{N}$-acyltransferase activity that catalyzes the intermolecular transfer of a fatty acyl group from a glycerophospholipid [e.g., phosphatidylcholine $(P C)$ ], to the ethanolamine moiety of phosphatidylethanolamine (PE), forming NAPE and lysophospholipid (e.g., lyso $P C$ ). Neuromodulators (e.g., VIP) may enhance $\mathrm{Ca}^{2+}$-dependent NAPE biosynthesis by activating a membrane receptor $(R)$ coupled to the activation of adenylyl cyclase $(A C)$ and to the subsequent stimulation of cAMP-dependent protein kinase $(P K A)$ activity. The broken arrow indicates that the molecular target of PKA leading to enhanced NAPE biosynthesis remains to be determined. NAPE is composed of several molecular species, differing in the fatty acyl group linked to the ethanolamine moiety (Schmid et al., 1990; Cadas et al., 1996). Therefore, cleavage of NAPE by a D-type phosphodiesterase activity [phospholipase D $(P L D)$ ] may give rise to multiple $N$-acylethanolamines (NAEs), including anandamide (which activates cannabinoid CB1-type receptors) and $N$-palmitoylethanolamine (which activates CB2-type receptors in certain cell types). Although cannabimimetic NAEs may be recovered in the extracellular fluid of stimulated neurons in culture (Di Marzo et al., 1994; Hansen et al., 1995), the mechanism of extrusion of these lipids (indicated schematically as a broken arrow) is still unknown.

other NAEs (Di Marzo et al., 1994; Cadas et al., 1996). Although this evidence supports a role of NAPE as NAE precursor, it does not rule out the possibility that additional, independent pathways of anandamide formation may exist. This is suggested by the ability of brain homogenates to catalyze the energy-independent formation of anandamide from nonesterified arachidonate and ethanolamine (Deutsch and Chin, 1993; Devane and Axelrod,
1994; Kruszka and Gross, 1994), a reaction that may be carried out by the reverse reaction of the degradative enzyme anandamide amidohydrolase (Ueda et al., 1995).

Prompted by the possible role of NAPE as NAE precursor, in the present study we have addressed a series of questions pertinent to the control of NAPE biosynthesis in brain tissue. Is the biosynthesis of NAPE regulated? And, if so, in which cell types 
and through what mechanism? The main results of our study are summarized in Figure 6.

We found that substances that stimulate NAE formationincluding the $\mathrm{Ca}^{2+}$ ionophore ionomycin and several chemically unrelated membrane depolarizing agents (Di Marzo et al., 1994) (present sludy) - are also effective in increasing the de novo biosynthesis of NAPE in cortical neurons in primary culture (Figs. 1-3). By contrast, we could not detect NAPE or stimulus-induced NAPE biosynthesis in cortical astrocyte cultures (Fig. 1d). A parsimonious interpretation of our results is that NAPE biosynthesis is restricted to neurons. We cannot exclude, however, the possibility that cultured astrocytes lose the enzymatic complement necessary to the formation of this phospholipid.

Stimulus-induced NAPE biosynthesis is $\mathrm{Ca}^{2+}$-dependent and occurs at $\left[\mathrm{Ca}^{2+}\right]_{\mathrm{i}}(120-150 \mathrm{nM})$ that are compatible with physiological stimulations (see Petrozzino et al., 1995). This result leads us to speculate that, during prolonged nerve activity, $\mathrm{Ca}^{2+}$ dependent NAPE biosynthesis may participate in replenishing the stores of NAPE depleted by phosphodiesterase-mediated formation of NAEs. Such a mechanism would be functionally analogous to that operative at monoaminergic synapses, where electrical activity evokes the $\mathrm{Ca}^{2+}$-dependent phosphorylation and consequent activation of tyrosine hydroxylase, the rate-limiting enzyme in catecholamine biosynthesis (Zigmond and Bowers, 1981; E1 Mestikawi et al., 1985).

Unlike the case of tyrosine hydroxylase, however, the regulation of NAPE biosynthesis by $\mathrm{Ca}^{2+}$ does not appear to involve calmodulin-dependent protein kinases or PKC, as suggested by the lack of effect of various pharmacological inhibitors of these kinases (Table 1). An alternative possibility, namely, that $\mathrm{Ca}^{2+}$ ions may act to stimulate NAPE biosynthesis directly, is supported by the existence in neurons of a $\mathrm{Ca}^{2+}$-dependent $\mathrm{N}$-acyltransferase activity (Fig. 5), absent from cultured astrocytes, which may catalyze the formation of NAPE via intermolecular transfer of a fatty acyl group from glycerophospholipid to the ethanolamine moiety of PE (Fig. 6). Such an activity was described previously in dog brain tissue, but its cellular localization and physiological regulation has remained elusive thus far (Natarajan et al., 1983; Schmid et al., 1990). Moreover, the results illustrated in Table 2 appear to rule out the participation in neuronal NAPE biosynthesis of other known mechanisms of amino group $\mathrm{N}$-acylation, including those implicated in the synthesis of NAPE in higher plants (Chapman and Moore, 1993) and of $N$-acylsphinganine in mammalian tissues (Kishimoto, 1983). While this study was under review, a similar $N$-acyltransferase activity was also described in rat testis (Sugiura et al., 1996).

Although protein phosphorylation is not likely to mediate $\mathrm{Ca}^{2+}$-dependent NAPE biosynthesis, our results suggest that it may exert an important modulatory function. This possibility is suggested by the marked potentiation that forskolin and VIP produce on the ionomycin-induced accumulation of NAPE (Fig. 4). In particular, we found that the potentiating effect of VIP occurs at concentrations $\left(\mathrm{EC}_{50}=400 \pm 42 \mathrm{nM}\right)$ similar to those required to activate adenylyl cyclase in cortical neurons $\left(\mathrm{EC}_{50}\right.$ $300 \pm 53 \mathrm{nM}$ ), and is prevented by the cAMP-dependent protein kinase inhibitor $\mathrm{H}-89$. The results indicate therefore that VIP, interacting with either VIP or PACAP receptor subtypes, potentiates $\mathrm{Ca}^{2+}$-dependent NAPE biosynthesis by stimulating cAMPdependent protein kinase activity. Thus, VIP-secreting neurons in the cortex, and possibly other brain modulatory systems positively linked to cAMP production, may participate with $\mathrm{Ca}^{2+}$ in a priming mechanism the consequence of which would be to in- crease the availability of NAPE for release of cannabimimetic NAEs. It will be important to determine whether a priming mechanism, such as that suggested here for cultured neurons, occurs also in the adult brain and plays a role in the functional interactions between cannabinoids and cAMP-linked brain reward systems (for review, see Gardner, 1992).

\section{REFERENCES}

Cadas H, Schinelli S, Piomelli D (1996) Membrane localization of $\mathrm{N}$-acylphosphatidylethanolamine in central neurons: studies with exogcnous phospholipases. J Lipid Med, in press.

Chapman K, Moore JT (1993) Catalytic properties of a newly discovered acyltransferase that synthesizes $N$-acylphosphatidylethanolamine in cottonseed (Gossipuim hirsutum L.) microsomes. Plant Physiol 102:761-769.

Colodzin M, Bachur N, Weissbach H, Udenfriend S (1963) Enzymatic formation of fatty acid amides of ethanolamine by rat liver microsomes. Biochem Biophys Res Commun 10:165-170.

Christie W (1987) HPLC and lipids: a practical guide, pp 23-25. Oxford: Pergamon.

Desarnaud F, Cadas H, Piomelli D (1995) Anandamide amidohydrolase activity in rat brain microsomes: identification and partial characterisation. J Biol Chem 270:6030-6035.

Deutsch D, Chin S (1993) Enzymatic synthesis and degradation of anandamide, a cannabinoid receptor agonist. Biochem Pharmacol 46:791-796.

Devane W, Axelrod J (1994) Enzymatic synthesis of anandamide, an endogenous ligand for the cannabinoid receptor, by brain membranes. Proc Natl Acad Sci USA 91:6698-6701.

Devane W, Hanuš L, Breuer A, Pertwee R, Stevenson L, Grittin G, Gibson D, Mandelbaum D, Etinger A, Mcchoulam R (1992) Isolation and structure of a brain constituent that binds to the cannabinoid receptor. Science 258:1946-1949.

Di Marzo V, Fontana A, Cadas H, Schinelli S, Cimino G, Schwartz J-C, Piomelli D (1994) Formation and inactivation of endogenous cannabinoid anandamide in central neurons. Nature 372:686-691.

El Mestikawi S, Gozlan H, Glowinski J, Hamon M (1985) Characteristics of tyrosine hydroxylase activation by $\mathrm{K}^{+}$-induced depolarization and/or forskolin in rat striatal slices. J Neurochem 45:173-184.

Facci L, Dal Toso R, Romanello S, Buriani A, Skaper SD, Leon A (1995) Mast cells express a peripheral cannabinoid receptor with differential sensitivity to anandamide and palmitoylethanolamine. Proc Natl Acad Sci USA 92:3376-3380.

Gardner E (1992) Marijuana/cannabinoids: neurobiology and neurophysiology. In: CRC series in physiology of drug abuse (Bartke LMA, ed), pp 275-335. Boca Raton, FL: CRC.

Giachetti A, Said S, Reynolds R, Koniges S (1977) Vasoactive intestinal polypeptide in brain: localization in and release from isolated nerve terminals. Proc Natl Acad Sci USA 74:3424-3428.

Grynkiewicz G, Poenie M, Tsien R (1985) A new generation of $\mathrm{Ca}^{2+}$ indicators with greatly improved fluorescence properties. J Biol Chem $260: 3440-3450$

Hansen H, Lauritzen L, Mette Strand A, Moesgaard B, Frandsen A (1995) Glutamate stimulates the formation of $N$-acylphosphatidylethanolamine and $N$-acylethanolamine in cortical neurons in culture. BBA 1258:303-308.

Hanson P, Schulman H (1992) Neuronal $\mathrm{Ca}^{2+} /$ calmodulin-dependent protein kinases. Annu Rev Biochem 61:559-601.

Hanuš L, Gopher A, Almog S, Mechoulam R (1993) Two new unsaturated fatty acid ethanolamines in brain that bind to the cannabinoid receptor. J Med Chem 36:3032-3034.

Hashimoto H, Ishihara T, Shigemoto R, Mori K, Nagata S (1993) Molecular cloning and tissue distribution of a receptor for pituitary adenylate cyclase-activating polypeptide. Neuron 11:333-342

Hazlewood G, Dawson M (1975) Intermolecular transacylation of phosphatidylethanolamine by a Butyrivibrio sp. Biochem J 150:521-525.

Hillard C, Wilkison D, Edgemond W, Campbell W (1995) Characterization of the kinetics and distribution of $\mathrm{N}$-arachidonylethanolamine (anandamide) hydrolysis by rat brain. Biochem Biophys Res Commun 1257:249-256.

Ishihara T, Shigemoto R, Mori K, Takahashi K, Nagata S (1992) Functional expression and tissue distribution of a novel receptor for vasoactive intestinal peptide. Neuron 8:811-819.

Kishimoto Y (1983) Sphingolipid formation. In: The enzymes (Boyer PD, ed), pp 363-372. New York: Academic.

Kruszka K, Gross R (1994) The ATP-and CoA-independent synthesis of arachidonoylethanolamine. J Biol Chem 269:14345-14348. 
Magistretti P, Morrison J (1988) Noradrenaline- and vasoactive intestinal peptide-containing neuronal systems in neocortex: functional convergence with contrasting morphology. Neuroscience 24:367-378.

Mechoulam R, Hanuš L, Martin B (1994) Search for endogenous ligands of the cannabinoid receptor. Biochem Pharmacol 48:1537-1544.

Natarajan V, Schmid P, Reddy P, Zuzarte-Augustin M, Schmid H (1983) Biosynthesis of $\mathrm{N}$-acylethanolamine phospholipids by dog brain preparations. J Neurochem 41:1303-1312.

Petrozzino J, Pozzo Miller L, Connor J (1995) Micromolar $\mathrm{Ca}^{2+}$ transients in dendritic spines of hippocampal pyramidal neurons in brain slice. Neuron 14:1223-1231.

Piomelli D (1994) Eicosanoids in synaptic transmission. Crit Rev Neurobiol 8:65-83.

Quick M, Iversen L, Bloom S (1978) Effect of vasoactive intestinal peptide (VIP) and other peptides on cAMP accumulation in rat brain. Biochem Pharmacol 27:2209-2213.

Schmid H, Schmid P, Natarajan V (1990) N-acylated glycerophospholipids and their derivatives. Prog Lipid Res 29:1-43.
Sugiura T, Kondo S, Sukagawa A, Tonegawa T, Nakane S, Yamashita A, Waku K (1996) Enzymatic synthesis of anandamide, an endogenous cannabinoid receptor ligand, through $N$-acylphosphatidylethanolamine pathway in testis: involvement of $\mathrm{Ca}^{2+}$-dependent transacylase and phosphodiesterase activities. Biochem Biophys Res Commun 218:113-117.

Ueda N, Kurahashi Y, Yamamoto S, Tokunaga T (1995) Partial purification and characterization of the porcine brain enzyme hydrolysing and synthetizing anandamide. J Biol Chem 270:23823-23827.

Venance L, Piomelli D, Glowinski J, Giaume C (1995) Inhibition by anandamide of gap junctions and intercellular calcium signalling in striatal astrocytes. Nature 376:590-593.

Walaas S, Greengard P (1987) Phosphorylation of brain proteins. In: The enzymes (Boyer PD, ed), pp 285-317. New York: Academic.

Zigmond R, Bowers C (1981) Influence of nerve activity on the macromolecular content of neurons and their effector organs. Annu Rev Physiol 43:673-673. 